11

\title{
Радиопоглощающие свойства феррит-полимерных композитов поливиниловый спирт/Ni-Zn феррит
}

\author{
() В.Г. Костишин, И.М. Исаев, Р.И. Шакирзянов, Д.В. Салогуб, А.Р. Каюмова, В.К. Олицкий \\ Национальный исследовательский технологический университет „МИСиС“, \\ 119049 Москва, Россия \\ e-mail: drvgkostishyn@mail.ru
}

Поступило в Редакцию 16 июля 2021 г.

В окончательной редакции 1 сентября 2021 г.

Принято к публикации 2 сентября 2021 г.

Изучены электромагнитные и радиопоглощающие свойства композитов с матрицей из поливинилового спирта с ферритовыми и токопроводящими включениями. В качестве основного наполнителя использовали порошок $\mathrm{Ni}-\mathrm{Zn}$-феррита шпинели марки $2000 \mathrm{HH}$ состава $\mathrm{Ni}_{0.32} \mathrm{Zn}_{0.68} \mathrm{Fe}_{2} \mathrm{O}_{4}$. Показано, что полученные композиты обладают эффективным радиопоглощением в диапазоне частот $2-5 \mathrm{GHz}$ с пиковыми значениями коэффициента отражения на металлической пластине менее $-20 \mathrm{~dB}$. На основе анализа спектров диэлектрической проницаемости, спектров магнитной проницаемости и рассчитанных спектров коэффициента отражения установлены критические факторы поглощения электромагнитных волн в полученных композитах.

Ключевые слова: полимерный композит, радиопоглощение, никель-цинковый феррит, поливиниловый спирт.

DOI: 10.21883/JTF.2022.01.51862.217-21

\section{Введение}

Широкое использование спутникового вещания, мобильной связи и телекоммуникационных систем в повседневной жизни человека создает повышенный уровень электромагнитного излучения (ЭМИ). Электромагнитные помехи (ЭМП) и электромагнитное загрязнение, вызванные повышенным фоном ЭМИ, являются наиболее актуальными проблемами XXI века. ЭМП могут понизить срок службы и долговечность электронных устройств, а электромагнитное загрязнение способно негативно влиять на жизнедеятельность живых организмов $[1,2]$. Для решения проблем с ЭМП активно разрабатываются материалы, поглощающие или экранирующие ЭМИ. Феррит-полимерные композиты, в особенности на основе ферритов-шпинелей, являются хорошими кандидатами на материалы, поглощающие ЭМИ $[3,4]$. Ферримагнетики обладают высокой намагниченностью насыщения, высокой диэлектрической и магнитной проницаемостями, что увеличивает потери композитных материалов и улучшает радиопоглощающие характеристики. Композиты с полимерной матрицей, содержащие ферриты, полупроводники (графен, металлические наночастицы), обладают выраженными радиопоглощающими и радиоэкранирующими свойствами благодаря сочетанию различных механизмов поглощения: естественного ферримагнитного резонанса (ЕФМР), резонанса движения доменных границ (РДГ), потери на вихревые токи, на переполяризацию, многократные отражения [5,6]. Поскольку частота ЕФМР ферритов-шпинелей лежит в радиодиочастотном диапазоне, который совпадает с рабочими частотами гражданских излучателей ЭМИ, ожидается, что композиты с ферритовыми включениями будут эффективными поглотителями в гражданском секторе [7-12]. Кроме того, микроструктурные особенности магнитных композитов на основе полимеров могут сильно влиять на спектры поглощения: размер, форма и концентрация магнитных и проводящих композитов могут изменять тип частотной дисперсии диэлектрической проницаемости и магнитной проницаемости, что влияет на частотное положение пика поглощения [13].

Поливиниловый спирт (ПВС) является полукристаллическим полимером с ненулевым дипольным моментом и высокой диэлектрической проницаемостью [14]. Ввиду своих уникальных свойств ПВС широко распространен. В современных исследованиях он часто используется в качестве биосовместимой полимерной матрицы, способной инкапсулировать наночастицы от сегрегации. Исследования, посвященные радиопоглощающим свойствам композитов на основе ПВС, проводились ранее. Так, в [15] композиты ПВС/восстановленный оксид графена/карбонильное железо получены смешиванием измельченного порошка железа с ПВС и оксидом графена. Данные композиты показывают отличные поглощающие свойства в микроволновом диапазоне (коэффициент отражения на металлической пластине $R_{l}=-35 \mathrm{~dB}$ на частоте $12 \mathrm{GHz}$ и полоса поглощения (ниже $-10 \mathrm{~dB}) \sim 8 \mathrm{GHz})$, которые обусловлены присутствием карбонильного железа (магнитные потери) и равномерно распределенным оксидом графена (диэлектрические потери). В других работах, посвященных композитам ПВС/углерод/Fe [16,17], показано, что возможно получение материалов с высокими потерями на отражение в диапазоне частот 4-8 GHz с коэффициентом $R_{l} \sim-(20-30) \mathrm{dB}$. Выраженные экранирующие свойства наблюдались в гибком композите с нанодиска- 
ми гексаферрита бария и сажей, внедренными в матрицу ПВС [18]. Эти композиты демонстрируют ослабление электромагнитных волн на $99.5 \%$ на интервале частот $8-18 \mathrm{GHz}$ с преобладающими диэлектрическими и магнитными потерями.

В настоящей работе исследуются электромагнитные характеристики феррит-полимерного композита на основе ПВС и порошка феррита-шпинели марки $2000 \mathrm{HH}$. Также производится анализ факторов, влияющих на поглощающие характеристики.

\section{1. Объекты и методики экспериментальных исследований}

Экспериментальные образцы были получены прессованием смеси порошков с нагревом. В качестве наполнителя для композитов использовали феррит-шпинель марки $2000 \mathrm{HH}$ с химическим составом $\mathrm{Ni}_{0.32} \mathrm{Zn}_{0.68} \mathrm{Fe}_{2} \mathrm{O}_{4}$. Спеченные изделия $\mathrm{Ni}-\mathrm{Zn}$-феррита измельчали в мельнице до получения порошка феррита фракции $<45 \mu \mathrm{m}$. В качестве матрицы использовался полимерный порошок марки ПВС 16/1. Порошки предварительно перемешивали до получения гомогенной смеси и загружали в пресс-форму. Образцы получали в виде колец с внешним диаметром $16 \mathrm{~mm}$, внутренним диаметром $7 \mathrm{~mm}$ и высотой $d=5-7.5 \mathrm{~mm}$ путем выдержки в течение $5 \mathrm{~min}$ при $150 \mathrm{MPa} \mathrm{и} \mathrm{температуре} 190^{\circ} \mathrm{C}$.

Комплексная магнитная проницаемость $\mu_{r}^{*}$, диэлектрическая проницаемость $\varepsilon_{r}^{*}$ и спектры коэффициента отражения на металлической пластине $R_{l}$ в диапазоне частот $0.01-7 \mathrm{GHz}$ были измерены с помощью коаксиальной ячейки и векторного анализатора Rohde \& Shwartz ZVL-13.

Состав полученных образцов представлен в табл. 1. Медная фольга и графит марки ГК-1 (сопротивление $4.5 \cdot 10^{-3} \Omega \cdot \mathrm{m}$ ) были использованы как проводящая добавка для композитов с массовыми долями 60 и $80 \%$ соответственно. Медная фольга, полученная деламинацией пленок толщиной $\sim 2 \mu \mathrm{m}$ со стеклянных подложек, добавлялась в смесь порошков феррита и полимера в количестве $3 \%$ по массовой доле. Массовая доля графита ГК-1 составляла 5\%.

Таблица 1. Состав экспериментальных образцов

\begin{tabular}{|c|c|c|}
\hline Состав & $\begin{array}{c}\text { Массовая доля } \\
\text { феррита, \% }\end{array}$ & $\begin{array}{c}\text { Объемная доля } \\
\text { феррита, \% }\end{array}$ \\
\hline$\Pi B C / \mathrm{Ni}-\mathrm{Zn}$ & 20 & 5 \\
\hline$\Pi B C / N i-Z n$ & 40 & 13 \\
\hline$\Pi B C / N i-Z n$ & 60 & 25 \\
\hline$\Pi B C / \mathrm{Ni}-\mathrm{Zn}$ & 80 & 47 \\
\hline$\Pi \mathrm{\Pi BC} / \mathrm{Ni}-\mathrm{Zn} / \mathrm{Cu}$ & 60 & 25 \\
\hline ПВС/Ni-Zn/графит & 80 & 47 \\
\hline
\end{tabular}

\section{2. Результаты эксперимента}

На рис. 1 показаны спектры диэлектрической проницаемости $\varepsilon_{r}^{\prime}(f)$ экспериментальных композитных образцов, чистого ПВС и феррита $\mathrm{Ni}-\mathrm{Zn}$. Видно, что с увеличением концентрации феррита увеличивается действительная часть диэлектрической проницаемости. Для всех экспериментальных образцов выраженной дисперсии спектров диэлектрической проницаемости в области $0.05-7 \mathrm{GHz}$ не обнаружено. Ниже этой области можно заметить „хвост“, который может принадлежать разным механизмам поляризации. Известно, что кристаллы с ионной связью, подобные ферритам шпинели $\mathrm{MeFe}_{2} \mathrm{O}_{4}$, имеют два механизма ионной поляризации: за счет смещения заряда и по прыжковому механизму (перемещение межузельного иона). Первый возникает на высоких частотах $10^{12}-10^{15} \mathrm{GHz}$ и характеризует свойства материала [19]. Второй механизм связан с дефектной структурой кристаллической решетки, когда межузельные ионы могут перемещаться на большое расстояние (порядка расстояния между атомами) под действием тепловых флуктуаций кристаллической решетки. Этот механизм работает на более низких частотах $\left(10^{4}-10^{7} \mathrm{~Hz}\right)$ и должен проявляться в ферритной керамике из-за наличия дефектов Френкеля и комплексной структуры (поликристаллические зерна и стеклообразные границы зерен). Более вероятно, что молотый феррит (после процесса измельчения) будет иметь большую концентрацию дефектов по сравнению с исходной ферритовой керамикой, что будет определять высокие диэлектрические потери, но спектры тангенса угла диэлектрических потерь $\left(\tan \delta_{\varepsilon}=\varepsilon_{r}^{\prime \prime} / \varepsilon_{r}^{\prime}\right.$ на вставке рис. 1) показывают противоположные результаты. Для всех композитов значение тангенса угла диэлектрических потерь не превышает 0.2 , а для неизмельченного керамического объемного образца $\mathrm{Ni}-\mathrm{Zn}$ оно достигает почти 0.6.

Сложная структура керамического феррита дает возможность образования объемных зарядов между высокоомными границами зерен и низкоомными зернами. Из-за прыжкового механизма проводимости в ферритах между ионами $\mathrm{Me}^{2+}$ и $\mathrm{Me}^{3+}$ (позиции А и В) электроны или дырки накапливаются на границах раздела между зернами и границами зерен и образуют объемные заряды $[20,21]$. В этой ситуации в области низких частот (ниже нескольких $\mathrm{MHz}$ ) происходит релаксационный процесс Максвелла-Вагнера. Некоторые исследования показывают, что дисперсия диэлектрической проницаемости в диапазоне частот $1-10 \mathrm{MHz}$ может быть связана с другим механизмом, когда частота скачка электронов между $\mathrm{Fe}^{2+}$ и $\mathrm{Fe}^{3+}$ совпадает с частотой приложенного поля, как в $\mathrm{Cu}-\mathrm{Zn}$ - или $\mathrm{Mn}-\mathrm{Zn}$-ферритах (и, вероятно, в ферритовой керамике $\mathrm{Ni}_{0.32} \mathrm{Zn}_{0.68} \mathrm{Fe}_{2} \mathrm{O}_{4}$, рассматриваемой в настоящей работе) $[22,23]$. В случае высокоомных композитов ПВС/Ni-Zn-феррита из спектров диэлектрической проницаемости можно сделать вывод, что в области $0.05-7 \mathrm{GHz}$ релаксационные процессы не про- 

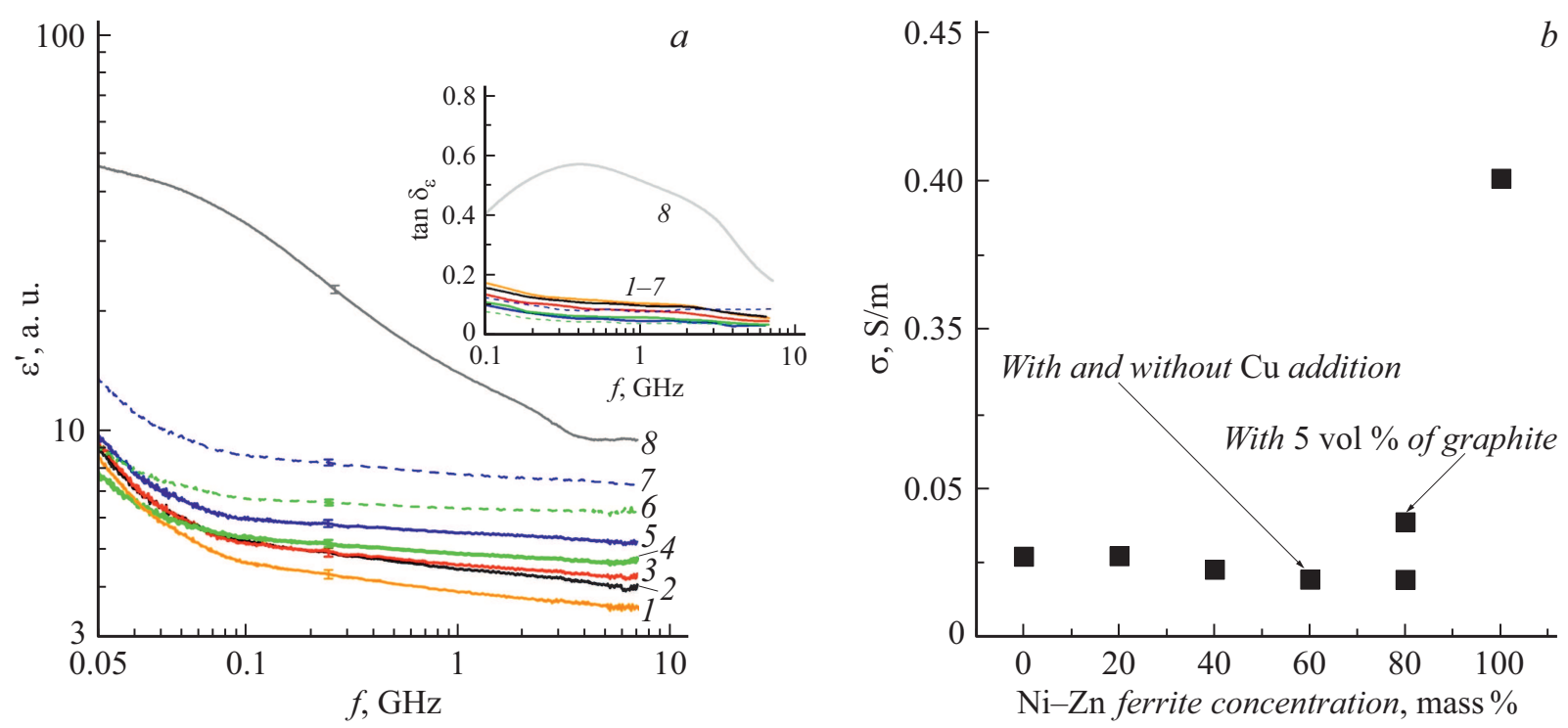

Рис. 1. $a$ - спектры диэлектрической проницаемости, $b$ - зависимость проводимости от концентрации феррита; на вставке спектры тангенса угла диэлектрических потерь. $1-$ ПВС, $2-20 \%$ ПВС/Ni-Zn, $3-40 \%$ ПВC/Ni-Zn, $4-60 \%$ ПВC/Ni-Zn, $5-80 \%$ ПВС/Ni-Zn, $6-60 \%$ ПВС/Ni-Zn и $\mathrm{Cu}, 7-80 \%$ ПВС/Ni-Zn, $8-$ объемный спеченный керамический феррит.

исходят. Для исходного спеченного объемного образца $\mathrm{Ni}-\mathrm{Zn}$-феррита форма спектров диэлектрической проницаемости и высокое значение тангенса угла диэлектрической проницаемости можно объяснить указанными выше механизмами. В случае полукристаллической матрицы ПВС все молекулярно-динамические релаксационные процессы имеют место в области низких частот и их признаки отсутствуют в области $0.05-7 \mathrm{GHz}$ [24].

График зависимости проводимости на частоте $1 \mathrm{GHz}$ от концентрации феррита представлен на рис. $1, b$. Видно, что нет существенной разницы в величине проводимости от концентрации феррита, но добавление графита увеличивает значение $\sigma$ вдвое. Относительно высокая проводимость неизмельченной ферритовой керамики $2000 \mathrm{HН} \mathrm{объясняется} \mathrm{наличием} \mathrm{выраженных} \mathrm{релакса-}$ ционных процессов. Следует отметить, что небольшая добавка микрофольги $\mathrm{Cu}$ в композит ПВC/Ni- $\mathrm{Zn}$ не увеличивает проводимость, что, скорее всего, связано с малой толщиной фольги и малой концентрацией (намного ниже порога перколяции).

Спектры магнитной проницаемости $\mu_{r}^{\prime}(f), \mu_{r}^{\prime \prime}(f)$ (рис. 2) также показывают, что с увеличением концентрации феррита среднее значение комплексной проницаемости увеличивается. Для всех составов в диапазоне частот $0.1-1 \mathrm{GHz}$ спектры проницаемости характеризуются выраженной дисперсией, связанной с двумя механизмами: резонансом движения доменной стенки (низкочастотная область) и вращением спина (собственный естественный ферромагнитный резонанс, высокая частота) [25]. Существенные различия магнитной проницаемости композитов с массовым содержанием 20 и $80 \%$ (и чистого объемного керамического феррита) объясняются разрывом магнитного потока в композитах с малой концентрацией. С увеличением концентрации феррита магнитный поток в композите усиливается, что увеличивает значение магнитной проницаемости. Следует отметить, что добавки с высокой проводимостью не изменяют значение магнитной проницаемости. Другой заметной особенностью спектров $\mu_{r}^{\prime}(f), \mu_{r}^{\prime \prime}(f)$ является большая разница в частотах дисперсии между ферритовой керамикой и композитами (рис. 2, $a$ и вставка). Вопервых, малый размер ферритовых частиц в композите не содержит большого количества магнитных доменов в своем объеме, поэтому низкочастотные максимумы на $\mu_{r}^{\prime \prime}(f)$, вызванные движением доменных стенок, не проявляются в спектрах композитов. Во-вторых, собственная резонансная частота, описываемая формулой $\omega_{\max }=H_{\mathrm{eff}} \cdot 4 \pi M_{\mathrm{s}}$, сильно зависит от магнитной анизотропии или от эффективного поля магнитной анизотропии $H_{\text {eff }}$ [26]. Основными факторами, влияющими на значение $H_{\text {eff }}$, являются магнитокристаллическая анизотропия, магнитно-дипольная анизотропия (поля размагничивания), анизотропия упругих напряжений (магнитоупругая анизотропия или магнитострикционная анизотропия), анизотропия формы, поверхностная магнитная анизотропия и т.д. [27]. Сдвиг частоты ЕФМР в высокочастотную область можно объяснить влиянием полей размагничивания, возникающих при введении немагнитной прослойки между магнитными частицами. Эти собственные поля размагничивания изменяют распределение намагниченности в объеме материала и увеличивают $H_{\text {eff. }}$

Тангенс угла магнитных потерь $\operatorname{tg} \delta_{\mu}=\mu_{r}^{\prime \prime} / \mu_{r}^{\prime}$ показан на вставке рис. $2, b$ в полосе частот $1-7 \mathrm{GHz}$. Видно, что при высоком содержании феррита $\mathrm{Ni}-\mathrm{Zn}(60$ и 80 mass.\%) в композитах значение $\tan \delta_{\mu}$ достигает $0.6-0.8$, а в исходной ферритовой керамике его значение снижается с 10 до 1. Из спектров проницаемости можно 

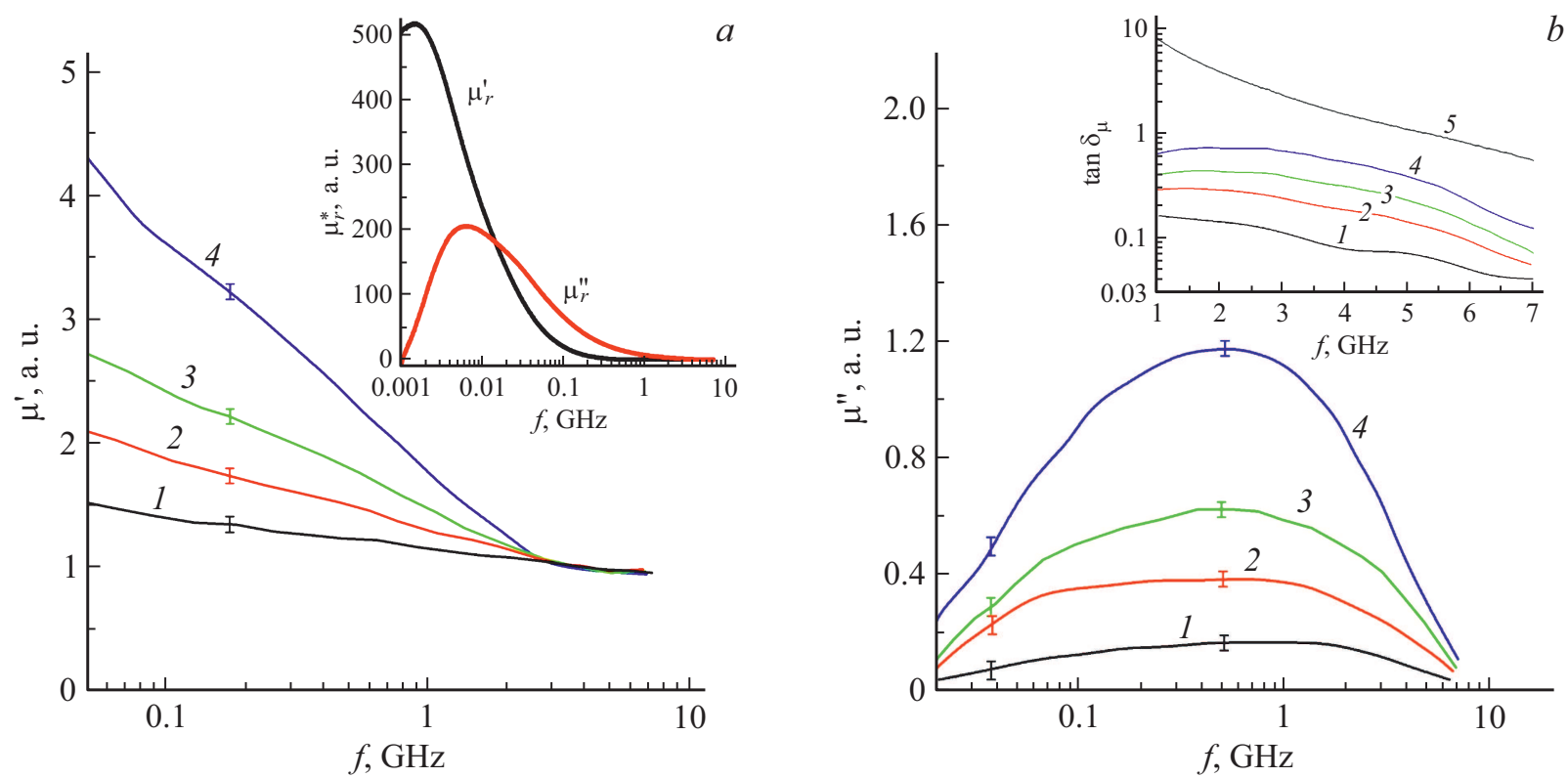

Рис. 2. Спектры действительной части магнитной проницаемости $(a)$ и мнимой части магнитной проницаемости $(b)$; на вставках - комплексные спектры проницаемости для спеченного керамического феррита $\mathrm{Ni}-\mathrm{Zn}$ и спектры тангенса угла магнитных потерь. $1-20 \%$ ПВС/Ni-Zn, $2-40 \%$ ПВС/Ni-Zn, $3-60 \%$ ПВC/Ni-Zn, $4-80 \%$ ПВС/Ni-Zn, $5-$ керамический объемный $\mathrm{Ni}-\mathrm{Zn}$-феррит.

сделать вывод, что высокое содержание магнитной фазы увеличивает магнитные потери в материале. По этой причине $\tan \delta_{\mu}$ ферритовой керамики значительно выше, чем для композитов ПВC/Ni-Zn. Сравнивая значения $\tan \delta_{\mu}$ и $\tan \delta_{\varepsilon}$ в диапазоне $1-7 \mathrm{GHz}$, можно утверждать, что магнитные потери в полученных композитах ПВC/Ni-Zn являются доминирующими.

Все вышеперечисленные процессы поляризации и магнитных резонансов обусловливают потери энергии электромагнитного излучения в композитах. Оценка поглощающих свойств композитов проводилась по величине коэффициента отражения на металлической пластине $R_{l}$. Расчетные спектры $R_{l}$ получены по формулам (1) и (2) с использованием спектров диэлектрической и магнитной проницаемости:

$$
\begin{gathered}
R_{l}=20 \log \left|\frac{Z_{\text {in }}-Z_{0}}{Z_{\text {in }}+Z_{0}}\right|, \\
Z_{\text {in }}=Z_{0} \sqrt{\frac{\mu_{r}^{*}}{\varepsilon_{r}^{*}}} \tanh \left[j \frac{2 \pi f d}{c} \sqrt{\mu_{r}^{*} \varepsilon_{r}^{*}}\right],
\end{gathered}
$$

где $Z_{0}-$ импеданс свободного пространства, $d-$ толщина поглотителя, $c$ - скорость света.

Трехмерные поверхности коэффициента на металлической пластине $R_{l}$ показаны на рис. 3. Как видно из рис. $3, a, b$, значительных потерь не наблюдается в композитах с 20\% и 40\% массовой доли феррита при варьировании толщины в пределах 4-10 mm. Интересный результат был получен для композита ПВС/Ni-Zn с $60 \%$. Введение малой концентрации медной фольги увеличивает пиковое поглощение с -14.6 до $-18.3 \mathrm{~dB}$.
Не исключено, что наличие $2 D$-проводящих объектов в структуре композита может создавать локальные области, в которых формируются множественные отражения, что создает дополнительные потери энергии электромагнитных волн. Аналогичные результаты получены в [28], где полые микросферы (ценосферы), покрытые наночастицами $\mathrm{Ag}$, вводились в полипиррольную матрицу. Комапозиты ПВС/Ni-Zn и ПВC/Ni-Zn/графит с 80 mass.\% феррита показывают хорошие поглощающие свойства при толщинах $8-10$ и 6-10 mm соответственно. Очень важно снизить массогабаритные параметры поглотителей, особенно для применений, связанных с военной техникой. По этой причине композит ПВС/Ni-Zn/графит более выгоден для практического применения, поскольку при толщине 5-10 mm этот композит имеет низкие значения коэффициента отражения на металлической пластине - менее $-10 \mathrm{~dB}$.

Чтобы установить факторы, влияющие на потери при отражении на металлической пластине, было проведено сравнение спектров $R_{l}(f)$ для разных образцов (табл. 2). Результаты показывают, что в поглотителях с большим $\left|R_{l}^{\max }\right|$ выполняется условие согласования импедансов $\left(Z_{\text {in }} / Z_{0}=1\right)$ и толщины интерференции $t_{m} \approx d[29,30]$. Сильное поглощение в композитах вызвано магнитными потерями, а также согласованием импедансов и толщины $t_{m}=c / 4 f \sqrt{ }\left|\mu_{r}^{*} \varepsilon_{r}^{*}\right|$ (когда толщина поглотителя равна расчетной интерференционной толщине $\left.t_{m} \sim \lambda / 4\right)$. При выполнении этих условий угловая разность фаз электромагнитных волн, отраженных от поверхности образца и отраженных от поверхности металла, составляет $\pi / 2$. Как видно из табл. 2, для композитов ПВC/Ni-Zn c 

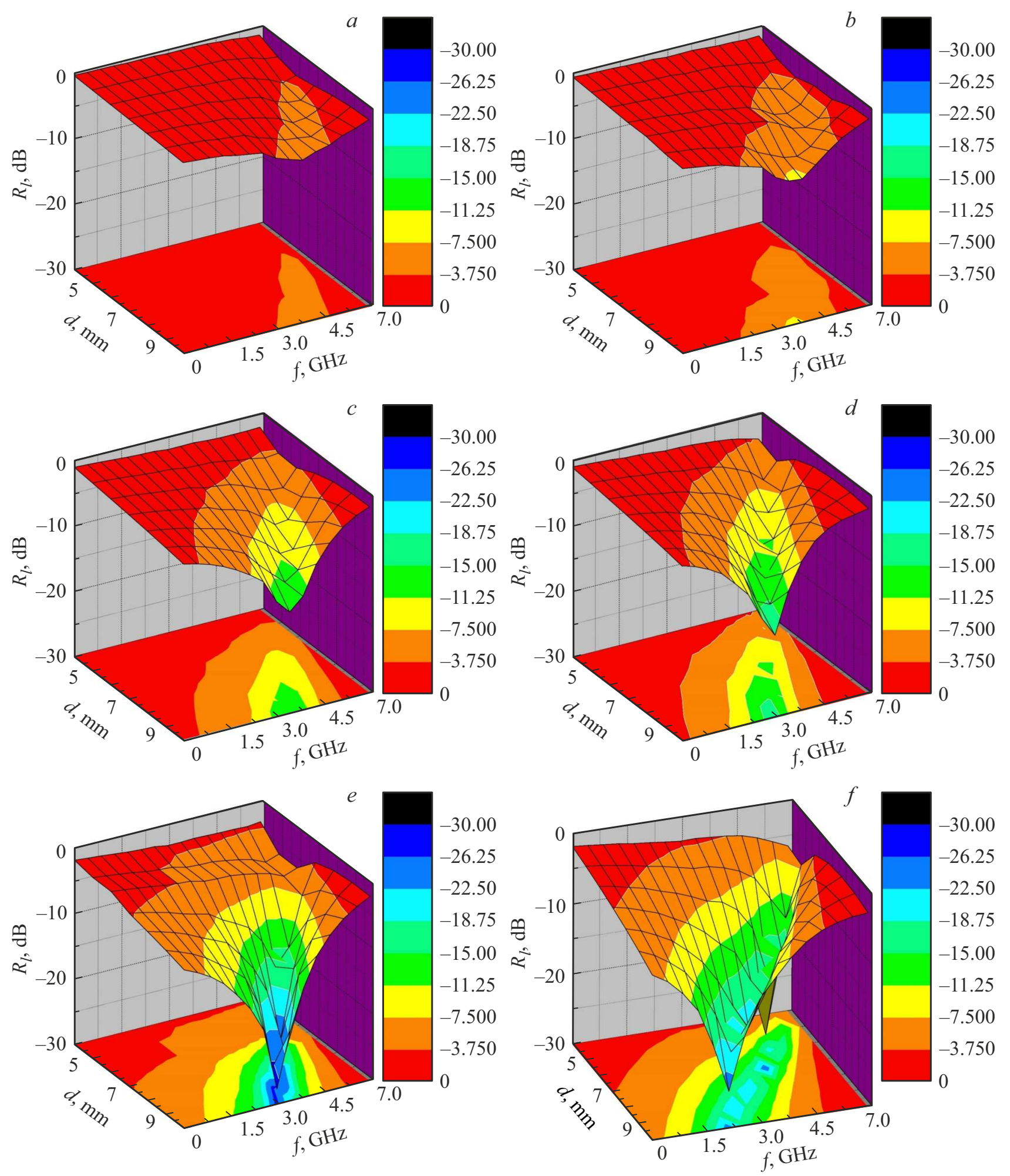

Рис. 3. Трехмерные поверхности коэффициента отражения на металлической пластине полученных композитов: $a-20 \% \Pi$ ПС $/ \mathrm{Ni}-\mathrm{Zn}, \quad b-40 \% \Pi \mathrm{\Pi BC} / \mathrm{Ni}-\mathrm{Zn}, c-60 \% \Pi \mathrm{CBC} / \mathrm{Ni}-\mathrm{Zn}, d-60 \% \Pi \mathrm{CB} / \mathrm{Ni}-\mathrm{Zn}$ и $\mathrm{Cu}, e-80 \% \Pi B C / \mathrm{Ni}-\mathrm{Zn}$, $f-80 \% \Pi \mathrm{\Pi BC} / \mathrm{Ni}-\mathrm{Zn}$ и графит.

содержанием 20, 40\% ни одно из этих условий не выполняется, что является причиной низкого значения коэффициента отражения. Также стоит отметить довольно большое значение полосы поглощения $\Delta f$ на уровне $-10 \mathrm{~dB}$ (поглощение 90\% энергии) для полученных композитов. Для расчетных спектров композитов с $80 \%$ содержанием феррита это значение составляет $\sim 2.3 \mathrm{GHz}$. При введении токопроводящих включений в 
Таблица 2. Сравнение параметров поглощения экспериментального и расчетного спектров $R_{l}(f)$ с нормированным импедансом и интерференционной толщиной

\begin{tabular}{|c|c|c|c|c|c|c|c|}
\hline Образец & $\begin{array}{c}\text { Массовая } \\
\text { доля } \\
\text { феррита, \% }\end{array}$ & $d, \mathrm{~mm}$ & $Z_{\text {in }} / Z_{0}$ & $t_{m}, \mathrm{~mm}$ & $f_{0}, \mathrm{GHz}$ & $\left|R_{l}^{\max }\right|, \mathrm{dB}$ & $\Delta f, \mathrm{GHz}$ \\
\hline ПВС/Ni-Zn & 20 & 7.0 & 3.38 & 6.50 & 5.65 & 4.5 & - \\
\hline ПВС/Ni-Zn & 40 & 6.0 & 2.91 & 6.50 & 5.65 & 5.6 & - \\
\hline$\Pi B C / N i-Z n$ & 60 & 7.0 & 1.80 & 6.15 & 5.86 & 9.2 & - \\
\hline$\Pi$ ПВС/Ni-Zn & 80 & 7.0 & 1.14 & 7.76 & 4.46 & 22.6 & 2.4 \\
\hline $\mathrm{PVA} / \mathrm{Ni}-\mathrm{Zn}$ & 60 & 10.0 & 1.47 & 10.3 & 3.71 & 14.6 & 1.2 \\
\hline$\Pi$ ПВС/Ni-Zn/Cu & 60 & 10.0 & 1.33 & 10.4 & 2.76 & 18.4 & 1.2 \\
\hline ПВС/Ni-Zn/Графит & 80 & 6.0 & 1.02 & 6.0 & 5.13 & 33.7 & 2.3 \\
\hline
\end{tabular}

композиты с ферритом $\mathrm{Ni}-\mathrm{Zn}$ возможно увеличение $\left|R_{l}\right|$ и уменьшение толщины согласования. Этот факт можно описать увеличением потерь на проводимость (вихревые токи) в композите ПВС/Ni- $\mathrm{Zn} /$ графит. Кроме того, с увеличением концентрации феррита частота максимума поглощения $f_{0}$ смещается в сторону более низких частот.

\section{Заключение и выводы}

Полученные композиты ПВС/ $\mathrm{Ni}_{0.32} \mathrm{Zn}_{0.68} \mathrm{Fe}_{2} \mathrm{O}_{4}$ были охарактеризованы высокочастотными измерениями диэлектрической и магнитной проницаемости. Спектры диэлектрической проницаемости показывают, что в диапазоне $0.05-7 \mathrm{GHz}$ выраженной дисперсии, вызванной процессами диэлектрической релаксации, не наблюдается. При измерениях динамической магнитной проницаемости была обнаружена дисперсия от процессов ЕФМР и РДГ. Высокое пиковое значение коэффициента отражения на металлической пластине менее $-10 \mathrm{~dB}$ в диапазоне частот $2-5 \mathrm{GHz}$ при толщине 6-10 mm было рассчитано для композитов с высоким содержанием феррита $(60,80 \%)$. В полученных композитах исключительно с ферритом $\mathrm{Ni}-\mathrm{Zn}$ преобладают магнитные потери. Введение проводящих добавок в композиты ПВС/ $\mathrm{Ni}-\mathrm{Zn}$ может улучшить поглощающие характеристики из-за потерь на вихревые токи и множественные отражения. Показано, что высокие характеристики поглощения в композитах определяются условием согласования импедансов и соответствием толщины поглотителя расчетной толщине интерференции.

\section{Финансирование работы}

Исследование выполнено за счет средств гранта Российского научного фонда (соглашение № 19-19-00694 от 06.05.2019 г.).

\section{Конфликт интересов}

Авторы заявляют, что у них нет конфликта интересов.

\section{Список литературы}

[1] D. Wanasinghe, F. Aslani. Composites Part B, 176, 107207 (2019). DOI: 10.1016/j.compositesb.2019.107207

[2] E.V. Yakushko, L.V. Kozhitov, D.G. Muratov, E.Yu. Korovin, A.A. Lomov, A.V. Popkova. Russ. Phys. J., 63 (12), 2226 (2021). DOI: $10.1007 / \mathrm{s} 11182-021-02292-8$

[3] D. Kumar, A. Moharana, A. Kumar. Mater. Today Chem., 17, 100346 (2020). DOI: 10.1016/j.mtchem.2020.100346

[4] S.B. Narang, K. Pubby. J. Magn. Magn., 519, 167163 (2021). DOI: $10.1016 /$ j.jmmm.2020.167163

[5] X. Zeng, X. Cheng, R. Yu, G.D. Stucky. Carbon, 168, 606 (2020). DOI: 10.1016/j.carbon.2020.07.028

[6] Z.W. Li, G.Q. Lin, Linfeng Chen, Y.P. Wu, C.K. Ong. J. Appl. Phys. 98, 094310 (2005). DOI: 10.1063/1.2128688

[7] V.G. Andreev, S.B. Menshova, A.N. Klimov, R.M. Vergazov, S.B. Bibikov, M.V. Prokofiev. J. Magn. Magn., 394, 1 (2015). DOI: 10.1016/j.jmmm.2015.06.007

[8] Р.И. Шакирзянов, В.Г. Костишин, А.Т. Морченко, И.М. Исаев, В.В. Козлов, В.А. Астахов. Журн. неорг. химии, 65(6), 758 (2020). DOI: 10.31857/S0044457X20060197 [R.I. Shakirzyanov, V.G. Kostishyn, A.T. Morchenko, I.M. Isaev, V.V. Kozlov, V.A. Astakhov. Russ. J. Inorg. Chem., 65 (6), 829 (2020). DOI: 10.1134/S0036023620060194]

[9] В.Г. Костишин, Р.М. Вергазов, С.Б. Меньшова, И.М. Исаев, А.В. Тимофеев. Заводская лаборатория. Диагностика материалов, 87 (1), 30 (2021). DOI: $10.26896 / 1028-6861-2021-87-1-30-34$

[10] В.Г. Костишин, Р.М. Вергазов, С.Б. Меньшова, И.М. Исаев. Рос. технол. журн. 8 (6), 87 (2020). DOI: $10.32362 / 2500-316 X-2020-8-6-87-108$

[11] И.М. Исаев, В.Г. Костишин, В.В. Коровушкин, Д.В. Салогуб, Р.И. Шакирзянов, А.В. Тимофеев, А.Ю. Миронович. ЖТФ, 91 (9), 1376 (2021). DOI: 10.21883/JTF.2021.09.51217.74-21

[12] M.A. Almessiere, Y. Slimani, A.V. Trukhanov, A. Baykal, H. Gungunes, E.L. Trukhanova, S.V. Trukhanov, V.G. Kostishin. J. Ind. Eng. Chem., 90, 251 (2020). DOI: 10.1016/j.jiec.2020.07.020

[13] A.V. Lopatin, N.E. Kazantseva, Y.N. Kazantsev, O.A. D'yakonova, J. Vilčková, P. Sáha. J. Commun. Technol. Electron., 53 (5), 487 (2008). DOI: $10.1134 / \mathrm{S} 106422690805001 \mathrm{X}$

[14] M. Aslam, M.A. Kalyar, Z.A. Raza. Polym. Eng. Sci., 58, 2119 (2018). DOI: 10.1002/pen.24855 
[15] Zhang Qi, Liu Chunbo, Wu Zhuang, Yang Yang, Xie Zhiyong, Zhou Haikun, Chen Chudong. J. Magn. Magn., 479, 337 (2019). DOI: 10.1016/j.jmmm.2018.11.129

[16] Y.K. Lahsmin, H. Heryanto, S. Ilyas, A.N. Fahri, B. Abdullah, D. Tahir. Opt. Mater., 111, 110639 (2021). DOI: 10.1016/j.optmat.2020.110639

[17] B. Abdullah, S. Ilyas, D. Tahir. J. Nanomater., 2018, 9823263 (2018). DOI: $10.1155 / 2018 / 9823263$

[18] S. Kumar, G. Datt, A.S. Kumar, A.C. Abhyankar. J. Appl. Phys., 120, 164901 (2016). DOI: 10.1063/1.4964873

[19] M.T. Sebastian. Dielectric Materials for Wireless Communication (Elsevier, Amsterdam, Boston, 2008)

[20] R. Metselaar, P.K. Larsen, in Proceedings of the International School of Physics Enrico Fermi (1978), v. 70, p. 417.

[21] В.Г. Костишин, Р.И. Шакирзянов, А.Г. Налогин, С.В. Щербаков, И.М. Исаев, М.А. Немирович, М.А. Михайленко, М.В. Коробейников, М.П. Мезенцева, Д.В. Салогуб. ФТТ. 63 (3), 356 (2021). DOI: 10.21883 FTT.2021.03.50586.230 [V.G. Kostishin, R.I. Shakirzyanov, A.G. Nalogin, S.V. Shcherbakov, I.M. Isaev, M.A. Nemirovich, M.A. Mikhailenko, M.V. Korobeinikov, M.P. Mezentseva, D.V. Salogub. Phys. Solid State, 63, 435 (2021). DOI: 10.1134/S1063783421030094]

[22] J. Parashar, V.K. Saxena, J. Sharma, D. Bhatnagar, K.B. Sharma. Macromol. Symp. 357 (1), 43 (2015). DOI: $10.1002 /$ masy.201400184

[23] P. Pengfei, Z. Ning. J. Magn. Magn. 416, 256 (2016). DOI: 10.1016/j.jmmm.2016.05.018

[24] N. Ghorbel, A. Kallel, S. Boufi. Composites Part A, 124, 105465 (2019). DOI: 10.1016/j.compositesa.2019.05.033

[25] S.B. Narang, K. Pubby. J. Magn. Magn., 519, 167163 (2021). DOI: $10.1016 /$ j.jmmm.2020.167163

[26] S. Chikazumi, C.D. Graham. Physics of Ferromagnetism, 2nd ed. (Clarendon Press, Oxford University Press, Oxford, NY., 1997)

[27] V. Babayan, N.E. Kazantseva, R. Moučka, I. Sapurina, Yu.M. Spivak, V.A. Moshnikov. J. Magn. Magn., 324 (2), 161 (2012). DOI: 10.1016/j.jmmm.2011.08.002

[28] R. Panigrahi, S. Srivastava. Sci. Rep., 5, 7638 (2015). DOI: $10.1038 /$ srep07638

[29] B. Wang, J. Wei, L. Qiao, T. Wang, F. Li. J. Magn. Magn., 324, 761 (2012). DOI: 10.1016/j.jmmm.2011.09.011

[30] Tao Wang, Rui Han, Guoguo Tan, Jianqiang Wei, Liang Qiao, Fashen Li. J. Appl. Phys., 112, 104903 (2012).

DOI: $10.1063 / 1.4767365$ 